(c) American Dairy Science Association, 2004.

\title{
Invited Review: $\beta$-Lactoglobulin: Binding Properties, Structure, and Function
}

\author{
G. Kontopidis, ${ }^{1}$ C. Holt, ${ }^{2}$ and L. Sawyer ${ }^{1}$ \\ ${ }^{1}$ Structural Biochemistry Group, \\ Institute of Cell and Molecular Biology, \\ The University of Edinburgh, \\ Swann Building, \\ King's Buildings, \\ Mayfield Road, Edinburgh, EH9 3JR, Scotland \\ ${ }^{2}$ Hannah Research Institute, \\ Ayr KA6 5HL, \\ Scotland
}

\begin{abstract}
$\beta$-Lactoglobulin ( $\beta$-LG) is the major whey protein of ruminant species and is also present in the milks of many, but not all, other species. Its amino-acid sequence and 3-dimensional structure show that it is a lipocalin, a widely diverse family, most of which bind small hydrophobic ligands and thus may act as specific transporters, as does serum retinol binding protein. Bovine $\beta$-LG binds a wide range of ligands, but this may not be the reason for its presence in milk. In reviewing the structure and physicochemical properties of the protein, we present the structures of the ligands cholesterol (at a resolution of $2.0 \AA, R=0.221 ; R_{\text {free }}=$ 0.295 ) and vitamin $\mathrm{D}_{2}$ (at a resolution of $2.4 \AA, \mathrm{R}=$ $0.212 ; \mathrm{R}_{\text {free }}=0.297$ ) each bound to the central binding cavity of bovine $\beta$-LG at $\mathrm{pH} 7.3$. Neither ligand is fully visible in the electron density maps, and the less wellordered regions are the polar end groups at the mouth of the binding site. In a separate experiment, a mercury ion was bound to the free Cys121 (at a resolution of $2.2 \AA, R=0.218 ; R_{\text {free }}=0.288$ ) in a way that transmitted a small structural change through Asp137 via Arg148 to the dimer interface. It is not clear if the known dissociation that arises from the reaction of $\beta$ - $\mathrm{LG}$ with $\mathrm{HgCl}_{2}$ results from this perturbation.
\end{abstract}

In reviewing the structural studies that reveal the ligand binding sites for long-chain fatty acids, retinoids, and steroids, only the central location, common to all lipocalins so far examined, is occupied under the conditions used. We find that there is no crystallographic evidence of another ligand binding site in our crystals grown in approximately $1.3 \mathrm{M}$ citrate, although low ionic strength studies in solution indicate the possible

Received: July 8, 2003.

Accepted: September 27, 2003.

Corresponding author: L. Sawyer; e-mail: l.sawyer@ed.ac.uk. presence of at least one other low affinity site. The apparent ability of the binding site to accommodate a wide range of ligands may point to a possible physiological function. However, by considering the lipocalin family in general, and the species distribution of $\beta$-LG in particular, some speculation as to the physiological function can be made. $\beta$-Lactoglobulin has been reported as being implicated, inter alia, in hydrophobic ligand transport and uptake, enzyme regulation, and the neonatal acquisition of passive immunity. However, these functions do not appear to be consistent between species. Sequence comparisons among members of the lipocalin family reveal that glycodelin, found in the human endometrium during early pregnancy, is the most closely related to $\beta$-LG. Although the function of glycodelin is also unknown, it appears to have effects on the immune system and/or to be involved in differentiation. It is proposed that $\beta$-LG, over-expressed in the lactating mammary gland of many, but not all, species, is primarily an important source of amino acids for the offspring of those animals that produce it, but that this function arose by gene duplication from the physiologically essential glycodelin. The other functions that have been associated with $\beta$-LG in the neonate are, therefore, fortuitous.

(Key words: $\beta$-lactoglobulin, cholesterol, vitamin $\mathrm{D}_{2}$, crystal structure, glycodelin)

Abbreviation key: RBP = retinol-binding protein.

\section{INTRODUCTION}

$\beta$-Lactoglobulin is the major whey protein of ruminant species, and its properties have been regularly reviewed (e.g., Tilley, 1960; Lyster, 1972; Kinsella and Whitehead, 1987; Hambling et al., 1992; Sawyer, 2003). It has been reported as being present in many (perhaps most) but not all, mammalian species with rodent, human, and lagomorph milks being notable by its absence. 
Whereas genetic variants of a single gene have been widely reported, particularly in the cow, several nonruminant species, such as the horse and the cat, have at least two distinct genes. Unlike the other main whey protein, $\alpha$-LA, which has a definite enzyme-modulation function in lactose synthase, $\beta$-LG does not apparently have any such identifiable function. The protein family to which $\beta$-LG belongs, the lipocalins (Flower et al., 2000), presents a widely diverse series of functions, most of which involve some ligand-binding function, and it has been speculated that a similar function must be the physiological reason for the significant quantities of $\beta$-LG found in milk (the domestic cow produces $\sim 2$ to $3 \mathrm{~g} \mathrm{~L}^{-1}$, dependent to varying extents on the breed, diet, and stage of lactation). Havea et al. (2001) have dealt in some detail with the aggregation and denaturation phenomena associated with milk processing. It is the purpose of the present paper to examine some of the molecular properties of the protein under more or less physiological conditions as they relate to the ligandbinding properties. In most of what will be described, it is the bovine protein to which reference is made. Finally, we shall consider the physiological function of the protein in light of these ligand-binding properties.

\section{THE STRUCTURE}

$\beta$-Lactoglobulin is a small protein, soluble in dilute salt solution as befits a globulin, with 162 amino acid residues $\left(\mathrm{M}_{\mathrm{r}} \sim 18,400\right)$ that fold up into an 8-stranded, antiparallel $\beta$-barrel with a 3 -turn $\alpha$-helix on the outer surface and a ninth $\beta$-strand flanking the first strand (see Figure 1). It is this strand that forms a significant part of the dimer interface in the bovine and ovine proteins but, while still present in porcine $\beta$-LG, is not involved in the formation of the dimer that forms at low $\mathrm{pH}$. The genetic variants referred to above in the ruminant species result in relatively minor amino acid differences, but the processing properties appear to be significantly affected even by these small changes, such that consideration has been given to removing the less favorable variants by selective breeding (Hill et al., 1997; Harris, 1997). The so-called calyx, or $\beta$-barrel, is conical and is made of $\beta$-strands A-D forming one sheet, and strands E-H forming a second. Strand A bends through a right angle such that the C-terminal end forms an antiparallel strand with $\mathrm{H}$; strands $\mathrm{D}$ and $\mathrm{E}$ also form a less significant interaction completely closing the calyx. It is this central cavity, the calyx, that provides the ligand-binding site. On the outer surface of the $\beta$-barrel, between strands $\mathrm{G}$ and $\mathrm{H}$, is the 3 -turn $\alpha$-helix. The loops that connect the $\beta$-strands at the closed end of the calyx, $\mathrm{BC}, \mathrm{DE}$, and FG are generally quite short, whereas those at the open end are significantly longer and more flexible.

In particular, the EF loop acts as a gate over the binding site. At low $\mathrm{pH}$, it is in the "closed" position, and binding is inhibited or impossible, whereas at high $\mathrm{pH}$ it is open, allowing ligands to penetrate into the hydrophobic binding site. The "latch" for this gate is Glu89, the residue implicated in the Tanford transition observed, although not identified, as having an abnormally high $\mathrm{pK}_{\mathrm{a}}$ (Tanford et al., 1959; Brownlow et al., 1997; Qin et al., 1998a).

The free Cys121, with its reactive thiol group, has a $\mathrm{pH}$-dependent activity that parallels that of the Tanford transition, and its involvement in the denaturation and aggregation behavior is now firmly established (Havea et al., 2001). The residue is situated on the outer surface of the $\beta$-barrel on strand $\mathrm{H}$, under the $\alpha$-helix, and quite some distance from the EF loop. The effect of this is to mask its accessibility to solvent, particularly at low $\mathrm{pH}$. Reaction with heavy metals like $\mathrm{Hg}^{2+}$ or $\mathrm{Cd}^{2+}$ does occur at most $\mathrm{pH}$ values and leads to a dissociation of the dimer. Indeed, reaction of the Cys with almost any thiol reagent appears to enhance dissociation into monomers (McKenzie and Sawyer, 1967; Hambling et al., 1992).

The CD and GH loops in many of the crystallographic analyses are indistinct, and the similarly indistinct nature of the extended $\mathrm{AB}$ loop led to the original misthreading of the amino acid sequence into the first electron density map (Papiz et al., 1986; Brownlow et al., 1997). $\beta$-Strand I is on the opposite side of strand A from strand $\mathrm{H}$ and forms an antiparallel interaction with the same strand of the second monomer. The other dimer-stabilizing interaction comes from the $\mathrm{AB}$ loop, where there is an ion pair from Asp33 of one subunit to Arg40 of the other. It is interesting to note that although strand I also exists in the porcine and equine $\beta$-LG structures, albeit with a slightly modified sequence, as do the Asp and Arg residues, no similar dimerization occurs at physiological $\mathrm{pH}$. Indeed, sitedirected mutagenesis designed to disrupt one or the other of these interactions, or better, both, produces a monomeric bovine protein (Sakurai and Goto, 2002; Wilson and Holt, to be published). There is no direct interaction between the $\alpha$-helixes, which are antiparallel on the outer surface of the molecule with the polypeptide chains, some $12 \AA$ apart. The closest approach of any atoms of the helix in the A subunit from the triclinic lattice $\mathrm{X}$ structure to the helix in the $\mathrm{B}$ subunit is $5.8 \AA$, and this involves the flexible side chains of Asp137A and Arg148B and vice versa.

The structure of $\beta$-LG has also been determined by NMR techniques by several groups (Belloque and Smith, 1998; Fogolari et al., 1998; Kuwata et al., 1998; Uhrinova et al., 2000) and includes the equine structure 
A

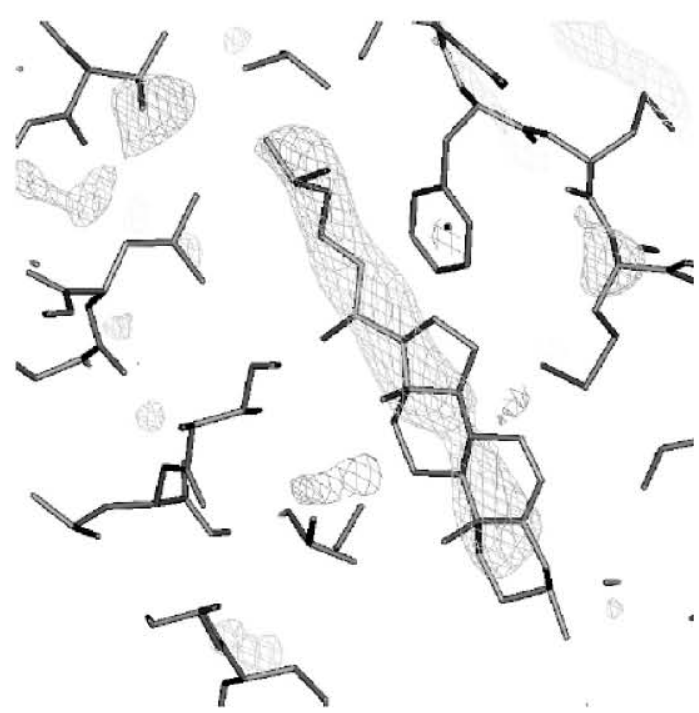

B

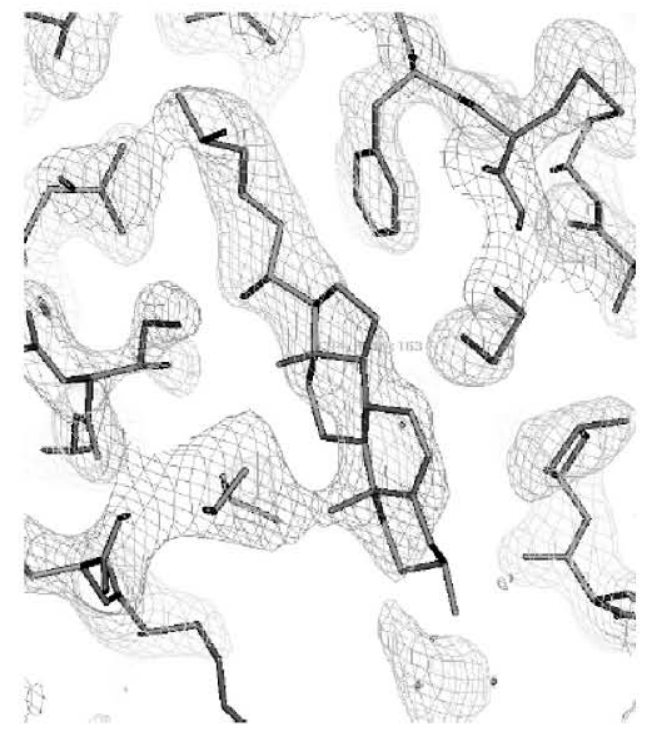

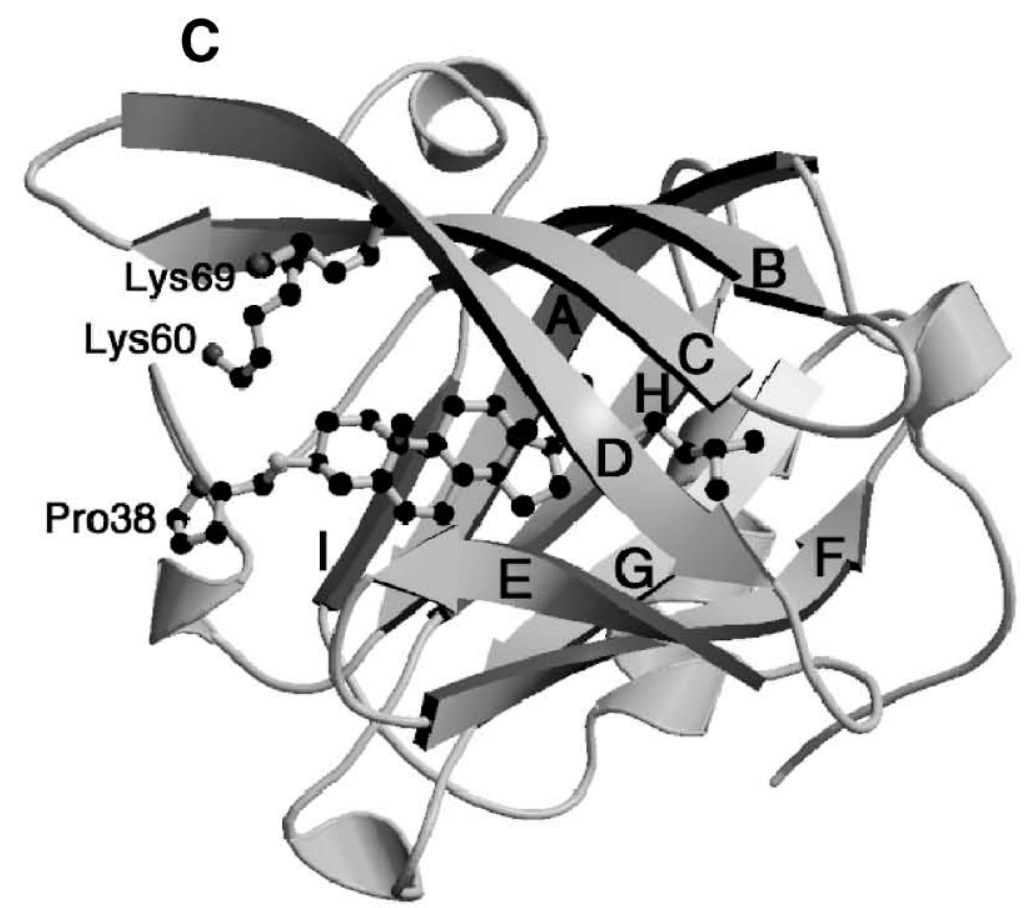

Figure 1. A. Initial difference electron density map around the internal binding calyx of bovine $\beta$-lactoglobulin complexed with cholesterol. The final model is also shown-Phe105 and Met107 on $\beta$-strand G are clearly visible to the right of the ligand. The contours are drawn at $2.3 \sigma$ for the map calculated with $\left(\left|\mathrm{F}_{\text {obs }}\right|-\left|\mathrm{F}_{\text {calc }}\right|\right)$ and $\alpha_{\text {calc. }}$. This and all other electron density diagrams were prepared with the program QUANTA. B. Final electron density map around the internal binding calyx of bovine $\beta$-lactoglobulin complexed with cholesterol. The contours are drawn at $2.2 \sigma$ for the map calculated with $\left(2\left|\mathrm{~F}_{\text {obs }}\right|-\left|\mathrm{F}_{\text {calc }}\right|\right)$ and $\alpha_{\text {calc }}$. C. An illustration showing the binding of cholesterol to the central cavity $\sigma$-lactoglobulin. The side-chains of Pro38, Lys60, and Lys 69 are shown as balls-and-sticks. The labeling of the $\beta$-strands is also shown. This and the other illustrations were prepared with the programs MOLSCRIPT (Kraulis, 1991) and RASTER3D (Merrit \& Bacon, 1997).

(Kobayashi et al., 2000). The bovine protein is monomeric at $\mathrm{pH}$ values below 3 , and the structure has been determined at this $\mathrm{pH}$. Although there is no matching crystal structure at this $\mathrm{pH}$ where flat hexagonal plates of poor diffraction quality can be grown, the structure of the core of the protein is well conserved. However, 
significant differences do exist, and these have been critically reviewed (Jameson et al., 2002); it is not surprising that it is the external loops that contain these major differences.

\section{Ligand Binding}

Reports that $\beta$-LG can bind ligands specifically date back to the middle of the last century when the binding of SDS was identified (McMeekin et al., 1949) and even before the fortuitous finding of the retinol- $\beta$-LG complex during a study of retinol-binding protein (RBP), to which it later emerged that $\beta$-LG is related, the binding of hydrophobic ligands to the protein was well established (Wishnia and Pinder, 1966; Lovrien and Anderson, 1969). Since then, many other ligands have been observed to bind to the protein by a variety of methods, including equilibrium dialysis, affinity chromatography, electron spin resonance spectroscopy, spectrophotometry, and perhaps the most popular, perturbation of the intrinsic Trp fluorescence (Sawyer et al., 1998; Sawyer, 2003). Nuclear magnetic resonance spectroscopy has also been used to monitor the binding of palmitic acid to the protein (Ragona et al., 2000). Several studies have shown that there appear to be more than one binding site on the protein monomer, but the exact location of the weaker site has not yet been achieved (Narayan and Berliner, 1997; Wang et al., 1997, 1998, 1999; Lange et al., 1998; Busti et al., 1998; Muresan et al., 2001).

The central, or main, ligand-binding site seems to accommodate linear molecules like fatty acids and also retinol with the cyclohexenyl ring system inside. It is clear that the lining of the pocket is very hydrophobic, and although we do not see any well-defined water or endogenous ligand molecules in the native protein as isolated from milk, it seems improbable that the calyx is actually empty; rather, there is only poorly ordered solvent, and/or a low occupancy of fatty acids (Perez et al., 1989), that cannot be detected above the noise in our experimental electron density. If all the molecules that can bind are bound within the cavity, then there is scope for binding nutritionally or medically useful molecules, either directly or after some modification to the protein's binding site (Skerra, 2000). However, such speculation is outside the scope of this article, although it is to the nature of the ligand binding site(s) of $\beta$-LG that this paper now turns, relying mainly on direct, crystallographic evidence.

\section{MATERIALS AND METHODS}

\section{Preparation of the Complexes}

Protein, ligands, and other chemicals were purchased from Sigma (St. Louis, MO). The general chemicals were of Analar or greater purity. A $20 \mathrm{mg} / \mathrm{mL}$ solution in $20 \mathrm{~m} M$ Tris $\mathrm{pH} 8.0$ of $\beta$-LG A was made to contain sufficient ligand stock solution (cholesterol, vitamin $\mathrm{D}_{2}$ : $50 \mathrm{~m} M$ ligand in ethanol) to give a molar ratio of one part protein to two parts ligand. The mixture was incubated for $2 \mathrm{~h}$ at $40^{\circ} \mathrm{C}$.

\section{Crystallization and Data Collection}

A solution of the $\beta$-LG-ligand complex was crystallized at $17^{\circ} \mathrm{C}$ by the hanging drop method using 1.25 $M$ sodium citrate, 0.1 $M$ HEPES, pH 7.3, as the precipitant. Each hanging drop contained $8 \mu \mathrm{L}$ of $\beta$-LG-ligand complex solution added to $8 \mu \mathrm{L}$ of the reservoir solution. After approximately $7 \mathrm{~d}$ at $17^{\circ} \mathrm{C}$, rhombohedral crystals of lattice $\mathrm{Z}\left(\mathrm{P} 3_{2} 21\right)$ had grown. For the mercury derivative, several crystals of the native protein of 0.2 to 0.3 $\mathrm{mm}$ in length were immersed in mother liquor containing $4 \mathrm{mM} \mathrm{HgCl}{ }_{2}$ and left for $1 / 2 \mathrm{~h}$ before mounting.

A crystal of 0.2 to $0.3 \mathrm{~mm}$ in length was collected in a 0.4-mm Cryoloop (Hampton Research Inc., Alisa Viejo, CA), dipped briefly in immersion oil (Type B, Cargille), and frozen by plunging into liquid $\mathrm{N}_{2}$. The frozen crystal was then transferred to a magnetic goniometer head in a stream of $\mathrm{N}_{2}$ at $100 \mathrm{~K}$ (Cryostream, Oxford Cryosystems, Oxford, UK). Diffraction data for the $\beta$-LG-vitamin $\mathrm{D}_{2}$ complex were collected in $1.5^{\circ}$ oscillations each of 30 min duration on a 300-mm MarResearch imaging plate system mounted on an ENRAF-Nonius FR571 rotating anode generator operating at $40 \mathrm{kV}$ and $80 \mathrm{~mA}$ and producing $\mathrm{Cu}-\mathrm{K} \alpha$ radiation from a graphite crystal monochromator. The $\beta$-LG-Hg complex data were collected in a similar manner on the Mar-FR571 system in Edinburgh. The $\beta$-LG-cholesterol complex data were collected at the CCLRC Daresbury Laboratory Synchrotron Radiation Source using station 9.5 with $\lambda=1.3 \AA$. All data were processed by DENZO and reduced with SCALEPACK (Otwinowski and Minor, 1997). Statistics for the data collection are shown in Table 1.

Refinement was performed using SHELXL (Sheldrick and Schneider, 1997) in the manner described fully for retinol binding to $\beta$-LG, starting from the refined $\beta$-LG lattice $\mathrm{Z}$ model without ligand (Wu et al., 1999). The refinement calculation was interleaved with rounds of model-building with the program WITNOTP (Widmer, 1997). Water molecules were added using the program SHELXWAT (Sheldrick and Schneider, 1997). After some 20 cycles of positional and individual Bfactor refinement interspersed with interactive modeling, the $\mathrm{R}$-factor for the $\beta$-LG-complex had dropped to around $28 \%$ with the $\mathrm{R}$-free around $36 \%$. The first difference electron density map $\left(\left|\mathrm{F}_{\mathrm{o}}\right|-\left|\mathrm{F}_{\mathrm{c}}\right|, \alpha_{\mathrm{c}}\right)$ calculated at this stage showed (Figures 1a, 2a, 3a) that the central calyx binding site was occupied by a molecule the size 
Table 1. Crystallographic data for $\beta$-Lg complexes with cholesterol, vitamin $\mathrm{D}_{2}$, and $\mathrm{HgCl}_{2}$.

\begin{tabular}{lccc}
\hline & Cholesterol & Vitamin $\mathrm{D}_{2}$ & Mercury \\
Data collection & SRS Daresbury & In-house & In-house \\
\hline Wavelength, $\AA$ & 1.3 & 1.542 & 1.542 \\
Unit cell $\mathrm{a}=\mathrm{b}, \AA$ & 53.4 & 53.7 & 53.8 \\
$\mathrm{c}(\AA) \alpha=\beta 0^{\circ} \gamma=120^{\circ}$ & 111.6 & 11.6 & 112.9 \\
Resolution range, $\AA$ & $45-2.0$ & $20-2.4$ & $20-2.2$ \\
Temperature, K & 100 & 100 & 100 \\
Oscillation range, & $79 \times 1$ & $117 \times 1.5^{\circ}$ & $90 \times 1.25^{\circ}$ \\
Exposure time, min & $2.5,0.16^{1}$ & 30 & 30 \\
Number of reflections collected & 17918 & 127784 & 155946 \\
Number of unique reflections & 13873 & 7791 & 10171 \\
Completeness of data, \% & 93.7 & 99.7 & 98.0 \\
Completeness last shell, \% & 100 & 99.8 & 97.2 \\
Redundancy & 8.5 & 16.4 & 15.3 \\
Mean I/ $\sigma(\mathrm{I})$ & 25.8 & 23.3 & 25.3 \\
$\mathrm{R}_{\text {merge }}{ }^{\circ} \%$ & 3.0 & 4.8 & 5.8 \\
$\mathrm{R}_{\text {merge }}$ last shell, \% & 17.6 & 22.0 & 31.8 \\
Refinement & & & \\
Final R-factor ${ }^{2}, \%$ & 22.1 & 21.2 & 21.8 \\
Reflections used & 7532 & 7609 & 9834 \\
Free R-factor $(\%$ of X-ray data) & $29.5(5)$ & $29.7(5)$ & $28.8(5)$ \\
Solvent sites & 114 & 116 & 136 \\
RMSD from ideality (bond length, $\AA$ ) & 0.005 & 0.004 & 0.006 \\
RMSD from ideality (bond angle distance, $\AA$ ) & 0.018 & 0.018 & 0.019 \\
Mean B-factor for protein atoms, $\AA^{2}$ & 44.5 & 57.27 & 50.0 \\
Mean B-factor for ligand atoms, $\AA^{2}$ & 69.9 & 72.6 & 53.5 \\
Mean B-factor for water molecules, $\AA^{2}$ & 53.0 & 56.9 & 55.9 \\
\hline
\end{tabular}

${ }^{1}$ The cholesterol data set resulted from combining high-resolution and low-resolution passes of $2.5 \mathrm{~min}$ and 10 sec.

$$
\begin{aligned}
& { }^{2} \mathrm{R}_{\text {merge }}=\Sigma_{\mathrm{hkl}} \mathrm{I}_{\mathrm{hkl}}{ }^{\text {obs }}-<\mathrm{I}_{\mathrm{hkl}}>\mid / \Sigma_{\mathrm{hkl}} \mathrm{I}_{\mathrm{hkl}}{ }^{\text {obs }} . \\
& { }^{3} \mathrm{R}=\Sigma_{\mathrm{hkl}} \|\left.\mathrm{F}_{\mathrm{hkl}}\right|^{\text {obs }}-\left.\left|\mathrm{F}_{\mathrm{hkl}}\right|^{\text {calc }}\left|/ \Sigma_{\mathrm{hkl}}\right| \mathrm{F}_{\mathrm{hkl}}\right|^{\text {jos }} .
\end{aligned}
$$

and shape consistent with its being cholesterol (Figure 1a) or vitamin $\mathrm{D}_{2}$ (Figure 2a). Refinement proceeded with the addition of water molecules, then the ligand was introduced, and positional and B-factor refinement continued. From the final electron density map calculated with coefficients $\left(2\left|\mathrm{~F}_{\mathrm{o}}\right|-\mid \mathrm{F}_{\mathrm{c}}, \alpha_{\mathrm{c}}\right)$ and shown in Figures $1 b$ and $2 b$, it was clear that much of the ligand fitted the density well, and further, there was no other significant electron density unaccounted for. The final statistics, including average temperature factors, are presented in Table 1.

Molecular diagrams were drawn with QUANTA (2000) or MOLSCRIPT (Kraulis, 1991), and other computations were carried out with the CCP4 Suite (CCP4, 1994).

\section{RESULTS}

The techniques employed were essentially those described by Kontopidis et al. (2002) for retinol. There is always some uncertainty in dealing with ligands that are only sparingly soluble in water, particularly in cases where the association is not particularly tight. We have adopted a method that works moderately well for crystallographic analysis but which, of course, requires a fairly high salt medium (typically $\sim 1.3 \mathrm{M}$ citrate) to grow and stabilize the crystals, a $\mathrm{pH}$ above 7 , to ensure the binding site is open and a significant protein concentration $(20 \mathrm{mg} / \mathrm{ml}, \sim 1 \mathrm{mM})$.

\section{Cholesterol}

Figure 1a shows the initial electron density map of the cholesterol- $\beta$-LG complex showing the ribbon of density in the same binding pocket that is occupied by fatty acids (Qin et al., 1998b; Wu et al., 1999) or retinol (Kontopidis et al., 2002). The electron density is not long enough to encompass the whole cholesterol molecule, and hence there was some ambiguity in building it into the available density. We assumed that the 3hydroxy group would not be buried in the center of the protein, and consequently modeled it such that a long hydrogen bond $(\sim 3.7 \AA)$ was formed with the carbonyl oxygen of residue Pro38 at the mouth of the calyx (Figure 1c). Refinement was carried out to improve this initial fitting, and the final statistics are shown in Table 1. The model is adequate and is certainly a plausible interpretation of the density. What was immediately obvious from the electron density map, however, was 

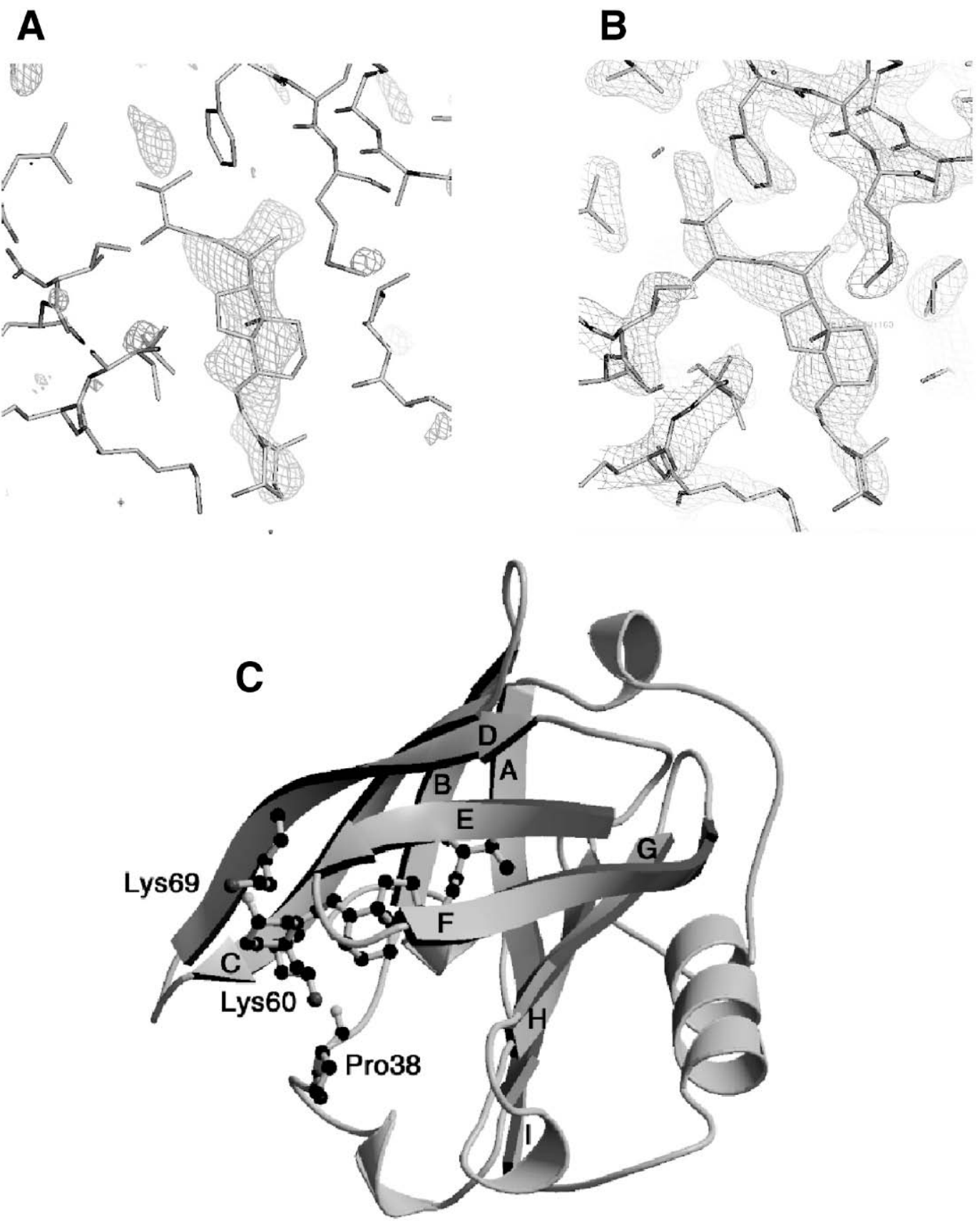

Figure 2. A. Initial difference electron density map around the internal binding calyx of bovine $\beta$-lactoglobulin complexed with vitamin $\mathrm{D}_{2}$. The final model is also shown. The contours are drawn at $2.3 \sigma$ for the map calculated with $\left(\left|\mathrm{F}_{\text {obs }}\right|-\left|\mathrm{F}_{\text {calc }}\right|\right)$ and $\alpha_{\text {calc. }}$ B. Final electron density map around the internal binding calyx of bovine $\beta$-lactoglobulin complexed with vitamin $\mathrm{D}_{2}$. The contours are drawn at $2.5 \sigma$ for the map calculated with $\left(2\left|\mathrm{~F}_{\mathrm{obs}}\right|-\mid \mathrm{F}_{\text {calc }}\right)$ and $\alpha_{\text {calc. }}$. C. An illustration showing the binding of vitamin $\mathrm{D}_{2}$ to the central cavity $\beta$-lactoglobulin. Notice that the 3 hydroxyl group is not interacting with Pro38 as in the case of cholesterol.

that part of the exposed fused-ring system of cholesterol was ill-defined in a manner reminiscent of the polar groups of the retinoids, retinal, and retinoic acid. A superposition of the cholesterol moiety with palmitic acid (Wu et al., 1999; Kontopidis et al., 2002) shows that the independently refined cholesterol occupies a broadly similar space and, although the degree of detail that is achievable in the structure reported here is less than one would hope for, there is little doubt that the binding that we observed is consistent with the association constant (Wang et al., 1997) and also with the other ligand-bound structures. 
A

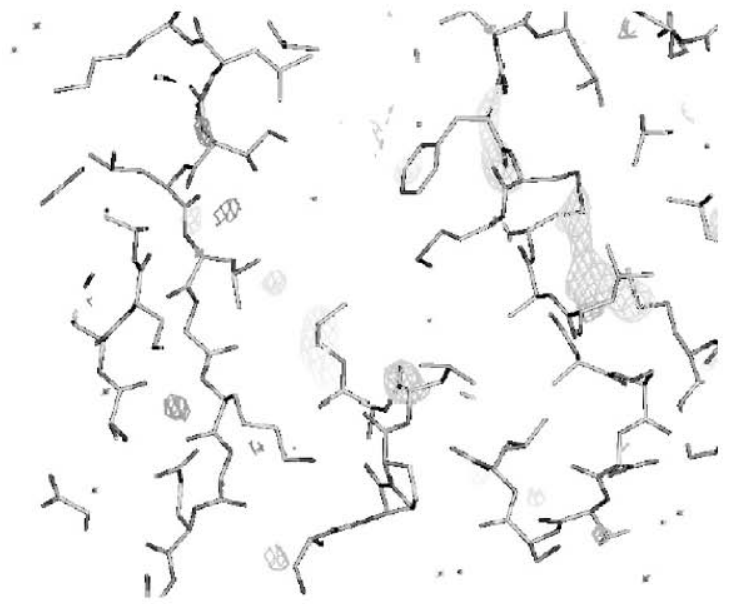

B

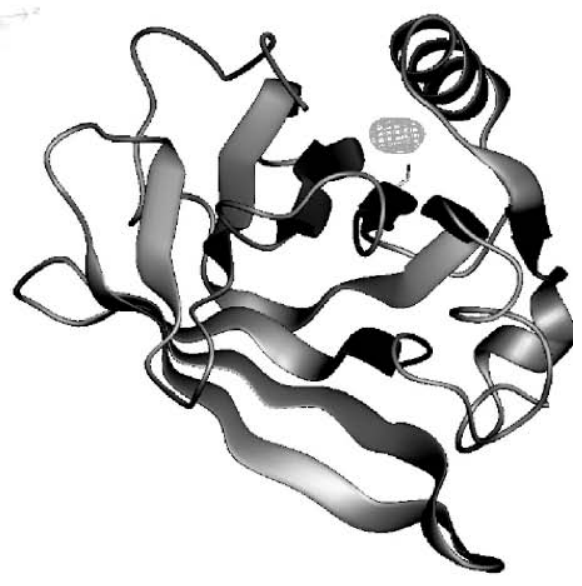

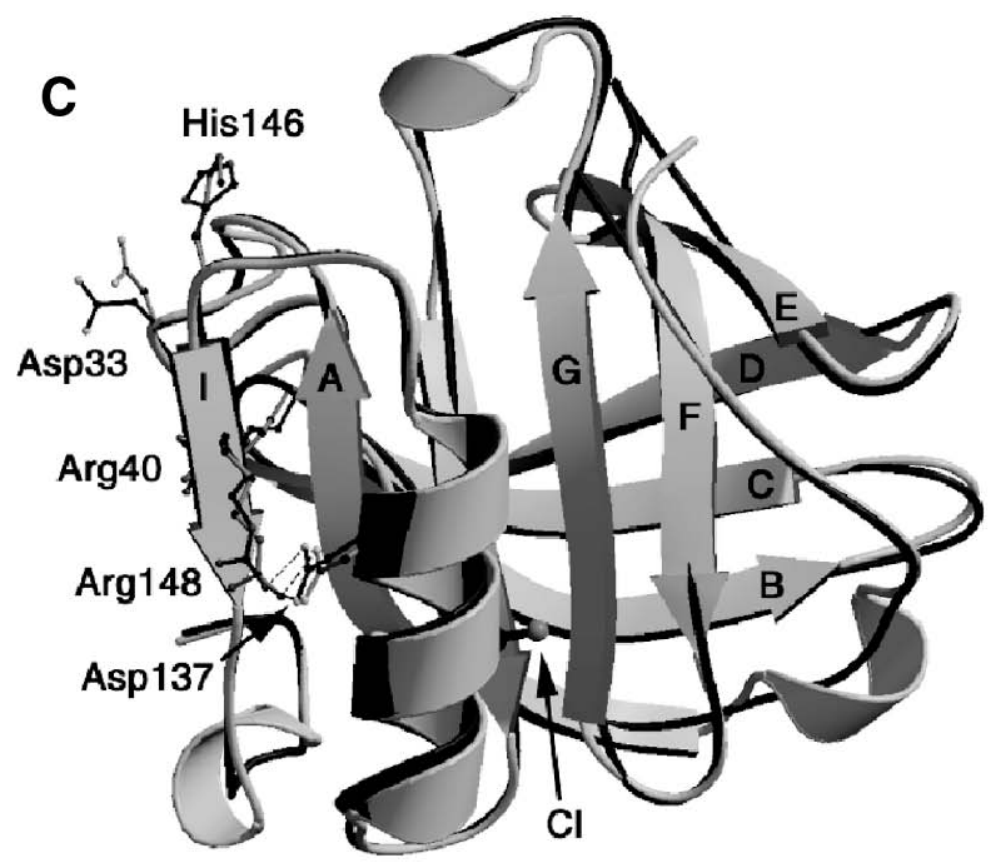

Figure 3. A. Initial difference electron density map around the internal binding calyx of bovine $\beta$-lactoglobulin complexed with mercuric chloride. The contours are drawn at $2.0 \sigma$ for the map calculated with $\left(\left|\mathrm{F}_{\text {obs }}\right|-\left|\mathrm{F}_{\text {calc }}\right|\right)$ and $\alpha_{\text {calc. }}$. It is clear that there is no electron density within the calyx binding site. B. Initial difference electron density map superimposed upon an illustration showing bovine $\beta$-lactoglobulin complexed with mercuric chloride. The contours are drawn at $5 \sigma$ for the map calculated with $\left(\left|\mathrm{F}_{\text {obs }}\right|-\left|\mathrm{F}_{\text {calc }}\right|\right)$ and $\alpha_{\text {calc. }}$. There is only the single peak showing the presence of a single, fully occupied mercury site.C. An illustration showing the effect of binding $\mathrm{HgCl}_{2}$ to the sulfur of Cys121. The superposition of the paler grey derivative structure is shown on the native cartoon (PDB: $1 \mathrm{bsq}$ ). The $\mathrm{Hg}-\mathrm{Cl}$ can just be seen pointing to the right under the central turn of the helix. The paler side of the helix indicates a small shift toward the dimer interface and an even smaller shift can just be seen in strand I to the right of the label for Arg40. The positions of the residues Asp137 and Arg148 that connect helix and strand I are shown together with Asp33, Arg40, His146, and Arg148. None of the side-chains around Cys121 are affected significantly.

\section{Vitamin $D_{2}$}

A similar situation arose with vitamin $\mathrm{D}_{2}$. The bulk of the electron density was not enough to cover the entire ligand, and so there was some difficulty in know- ing which end should be inserted into the binding calyx (Figure 2a). The refinement statistics (Table 1) did not discriminate between either of the two principal binding modes (that with the hydroxyl group innermost, and that with it in the more chemically reasonable external 
arrangement), and we have, therefore, chosen that with the hydroxyl group bound externally. In this case, however, the 3-hydroxyl group appears to form an H-bond with the carbonyl of Lys 69, and that of Pro38 interacts with Lys 60 (Figure 2b). Once again, the electron density is poor for the outer extremity of the ligand but, in this case, the innermost aliphatic chain is also less well defined than in cholesterol, retinal, or palmitate.

\section{Mercury Ion}

A mercury derivative made by reaction with the free cysteine of $\beta$-LG was used to solve the original crystal structure by multiple isomorphous replacement (Brownlow et al., 1997), and it seemed worth revisiting that experiment in order to examine the effect on the structure, since it was known that modifying Cys121enhanced dimer dissociation (McKenzie and Sawyer, 1967; Hambling et al., 1992; Sakai et al., 2000). Data collected from a soaked crystal produced the expected large peak close to the $\mathrm{S} \gamma$ of Cys121 (Figure 3a, b) and, further, Figure 3a shows that there is no ligand discernible in the central binding pocket, although, following refinement, there is evidence of a second, weaker binding site near the extremity of the EF loop. When the structure of the native protein in the same space group was superimposed using the core $\beta$-strands F, G, and $\mathrm{H}$ that support Cys121, it was found that there was very little obvious movement within the dimer interface; the helix did not move significantly relative strands F, G, and H, nor did strand I (Figure 3c). Several sidechains had moved, although, in some cases, this does not affect the other subunit. Glu131, Glu134, and Lys138 on the upper surface of the helix had adopted different conformations - the ring of Phe136 had rotated by some $25^{\circ}$ and that of His 146 on strand I by about $90^{\circ}$. Whereas the guanidino group of Arg40 remained largely unmoved, the sidechain of Asp33 had rotated by approximately $90^{\circ}$ around $\chi_{1}$. This would affect the ion pair interaction between Asp33 and Arg40, which is part of the interface that holds the dimer together (Brownlow et al., 1997; Sakurai and Goto, 2002). Perhaps most significantly, the side chain of Arg 148 in the center of strand I at the dimer interface is hydrogen bonded to Asp137 on the helix. Thus, any small movement of the helix will be transmitted to the central side chain of the crucial interfacial $\beta$-strand. However, it is unclear why this should result in dissociation, since Arg in particular has a long and flexible side chain, capable of absorbing small movements caused by a slight roll in the helix toward the interface, produced when the $\mathrm{Hg}$ atom binds. The I strand hardly moves at all (Figure 3c). It is even less clear at this stage why this binding should have any effect on Asp33 or Arg40, some 20 and $15 \AA$ from the Asp and Arg residues, respectively.

\section{DISCUSSION}

The evidence presented here is consistent with all of the structure-based binding studies on the lipocalin family in that the observed binding site for hydrophobic ligands with moderately low dissociation constants is within the central calyx of the structure. No evidence for binding at an alternative site was obtained, although the work from other laboratories, most notably those of Swaisgood and de Wolf (Wang et al., 1997, 1998, 1999; Muresan et al., 2001), provides a possible explanation for the diverse reports of more than a single binding site. It appears that discrepancies in the reported ligand affinities may be method-dependent. Using the intrinsic fluorescence of Trp can give results that indicate significantly tighter ligand binding than other methods, especially equilibrium dialysis. This effect is particularly noticeable in the case in which the Trp fluorescence decreases on ligand addition (Muresan et al., 2001). Taken together with the wide diversity of shapes of ligand that have been reported to bind to $\beta$ LG (Sawyer, 2003), a surface binding site with a low affinity together with the main, central site would appear to satisfy most of the reported experimental observations. A crystallographic analysis, particularly of a sparingly soluble ligand, is unlikely to show a distinguishable binding site when the $\mathrm{K}_{\mathrm{d}}>10 \mu M$, and this may well be why we have been unable to locate any other binding site on the protein.

The location of this putative second binding site is also uncertain. The original report of retinol binding by $\beta$-LG would appear to be in error (Brownlow et al., 1997), and although it is tempting to assign the site to the region around the free thiol group "under" the helix on the outer surface of the protein, there is no structural evidence for this being the case, with the exception of those ions and molecules that are known to react with cysteine. However, the distinct structural variability of binding of the polar ends of the various ligands, where the protein also has a relatively open "vestibule" at the mouth of the calyx, could indicate that this may be a subsidiary site. It is certainly large enough to accommodate a second molecule when the ligand is small (Wishnia and Pinder, 1966).

It is known that reaction of the free thiol at Cys121 increases the monomer concentration over that of the dimer, and it has also been shown that it takes only a relatively small change to the interface to dissociate the molecule (McKenzie and Sawyer, 1967; Burova et al., 1998; Sakai et al., 2000; Sakurai and Goto, 2002). By soaking mercury ions into crystals of $\beta$-LG, it has 
been possible to trap an otherwise unstable state of the protein, and the small changes that occur involving the helix residue Asp137 and Arg148 on the I-strand at the dimer interface, show that a modification, remote from the interface, can be transmitted to it and thereby may enhance dissociation. Dissociation is believed to occur before unfolding and disulphide interchange during the thermal denaturation of $\beta$-LG (Qi et al., 1997; Manderson et al., 1999), and so this structure may represent an early stage of the unfolding pathway.

No definite physiological function has been ascribed to $\beta$-LG, although several suggestions have been made, the more compelling of which favor a role in molecular transport or, possibly, as some form of modulator (Kontopidis et al., 2002). Most suggestions concerning the function, understandably, have concentrated on either the lactating cell or more usually the neonate, and a transporter role seems reasonable, since many lipocalins are transporters. $\beta$-Lactoglobulin binds both fatty acids and retinol, and the structure is similar to the known transporter, plasma RBP. The nature of the ligand transported, apart from being generally hydrophobic, is not clear, however. Fatty acids, rather than retinal, are found as endogenous ligands in milk, but not all species have a $\beta$-LG that binds fatty acids (Perez et al., 1989, 1993), and it seems improbable that the true function will vary from species to species. Similarly, retinol is significantly more soluble in the fat phase of milk and thus will probably be transferred from mother to offspring by that route. A signaling or activity-modulator role appears to be less likely, not just because of the paucity of similar roles reported for other lipocalins (Flower et al., 2000), but also because the data supporting these various activities appear rather circumstantial. Further, for such an important role, one might expect the presence of $\beta$-LG in the milks of all species, not just some. What does not appear to have been considered in detail until recently (Kontopidis et al., 2002) is that the function is directly related to maternal physiology.

When the species variation of $\beta$-LG sequences is examined along with that of the other lipocalins, what emerges is a family tree like that shown in Figure 4. The RBP are clearly distinct from the lactoglobulins, but there is one protein present in the endometrium, now called glycodelin (formerly PP14, inter alia), that is the closest relative to the $\beta$-LG-II gene product (Halttunen et al., 2000; Seppälä, 2002). There are also reports of RBP expressed in the endometrium of cow (Thomas et al., 1992; MacKenzie et al., 1997). Notice also that there is ruminant pseudo-gene identified in both cow and goat that is also most nearly related to the sequence of $\beta$-LG-II. Might it be that the protein glycodelin reflects the true, original function of $\beta-\mathrm{LG}$ as a protein involved in some aspect of fetal development in all mammals? In many species, the gene has undergone a gene duplication event and is expressed during lactation for nutritional purposes. More recently, some species, like rodents, lagomorphs, and man, have lost the function of one of these genes through formation of a pseudo-gene, resulting in the gene ceasing to be expressed. The biological properties of the milk protein, such as ligand binding and inhibiting harmful bacterial adhesion in the intestine (Ouwehand et al., 1997) that have been identified, are clearly useful to each species but are subsidiary to those of neonatal nutrition. On the other hand, it is known that low levels of $\beta$-LG are expressed in the cow throughout the dry period in a manner that is distinct from $\alpha$-LA and the caseins (Aslam et al., 1994). Whether this is indicative of another more physiological role for $\beta$-LG in the changes that occur to the mammary gland during this period remains unclear at present.

Baboon (Papio hyandras) appears to have both $\beta$-LG and glycodelin (A.T. Fazleabas, personal communication) and two obvious questions arise. First, is there a pseudo-gene for $\beta$-LG in the human genome? Second, does the ruminant endometrial tissue contain glycodelin? In a preliminary experiment, searching the annotated human genome (Altschul, 1997) with the human glycodelin protein sequence produced a large number of lipocalin sequences, most of which are not lactoglobulins. However, several fragments that may be pseudogenes have been identified and are undergoing further analysis. It also appears that the pseudogene identified by Pena et al. (2001; NCBI: AH011480, AF403023/ 24/25 http://www.ncbi.nih.gov/entrez/viewer.fcgi?187 65895) may be just isolated exons of glycodelin; at least the alignment of the DNA shows a perfect match to part of that coding for glycodelin. Attempts at detecting glycodelin, as distinct from RBP, in the fetuses of sheep or cattle are yet to be attempted.

Intriguingly, the molecular function of glycodelin during fetal development is not clearly understood either (Mukhopadhyay et al., 2001; Seppälä et al., 2002), but the similarity with $\beta$-LG described above clearly implies involvement of some essential small molecule. A retinoid of some sort is an obvious possibility because of the similarity to RBP, but neither retinol nor retinoic acid appear to bind to glycodelin (Koistinen et al., 1999). However, the results obtained above indicate a steroid being a possible ligand, further supported by the only lipocalin with enzymic activity being prostaglandin synthase (Tanaka et al., 1997). Some involvement with long-chain or polyunsaturated fatty acids such as arachidonic acid, a precursor of prostaglandins, would provide a possible alternative physiological ligand, al- 


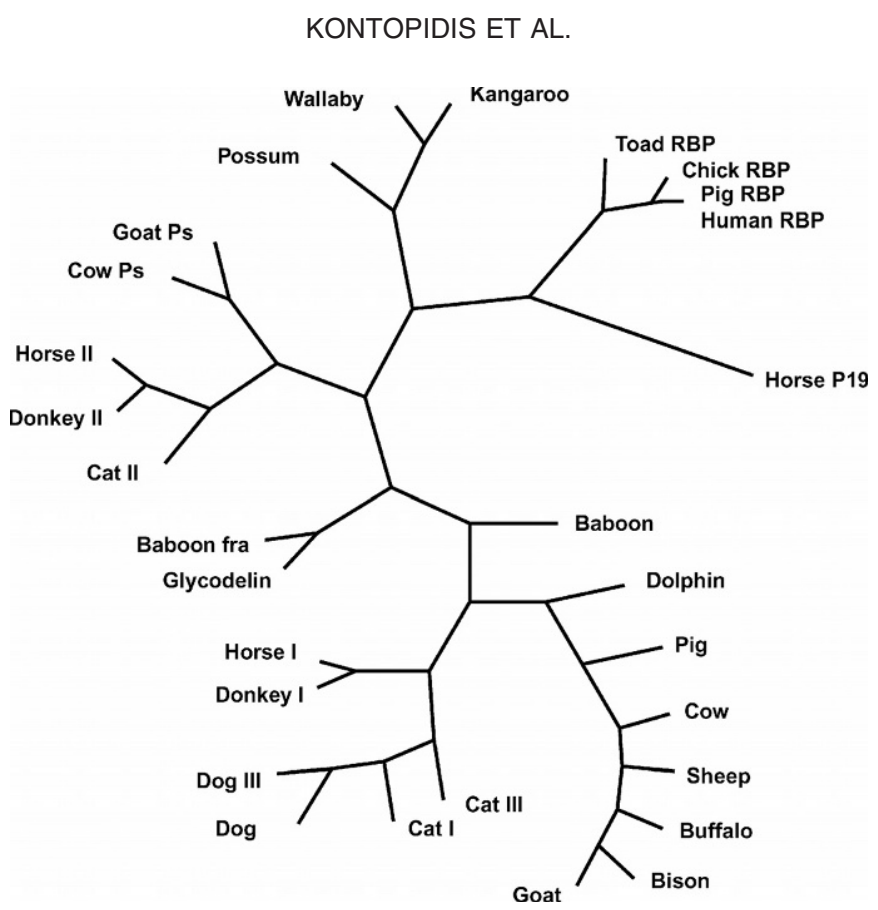

Figure 4. A sequence-based cladogram showing the family tree of $\beta$-lactoglobulin, glycodelin, and retinol binding protein. The diagram is not drawn to scale. The alignment was carried out by Andrew Coulson, and TREEVIEW (Page, 1996) was used to produce the diagram. The proteins used in the alignment did not have their signal sequence present, and the sequences were from the SwissProt databank (Bairoch and Apweiler, 2000) except the cow pseudo-gene (Passey and Mackinlay, 1995): Cow-P02754; Buffalo-P02755; Goat-P02756; Goat pseudo-gene-Z47079; Sheep-P02757; Dolphin-B61590; Pig-P04119; Dog-P33685; Dog III-P33686; Cat I-P33687; Cat III-P33688; Donkey I-P13613; Horse I-P02758; Donkey II-P19647: Horse II-P07380; Cat II-P21664; Baboon-AF021261; Glycodelin-P09466; Wallaby-Q29614; Kangaroo-P11944; Possum-Q29146. For RBP: Toad-P06172; Chicken-P41263; Rat-P27485; Human-P02753; Horse P19-Q28388.

though there are no reports of this interaction. There is clearly considerable scope for further work in the area.

\section{CONCLUSIONS}

We report here the medium resolution structures of complexes of bovine $\beta$-LG with cholesterol, vitamin $\mathrm{D}_{2}$, and with mercury ions. The electron density for the two organic ligands is not sufficient to provide unambiguous evidence for the exact location of all atoms in the structure, but the likely arrangement is that with the hydrophobic ends being innermost. From the structure of the mercury-Cys121 complex, we are unable to identify with certainty why modification of Cys121 destabilizes the dimer.

Based on the species distribution and lipocalin family relationships, a function is proposed that accounts for much of the interspecies variation in properties.

\section{ACKNOWLEDGMENTS}

Financial support from the BBSRC and a European Union Concerted Action is gratefully acknowledged. We are grateful to many friends and colleagues but particularly to Mike Boland, Stella Bury, Andrew Coulson, Lawrie Creamer, Geoff Jameson, Mahesh Narayan, and
Su-Ying Wu for stimulating discussions and to the MADGELAS partners for their continued interest.

\section{REFERENCES}

Altschul, S. F., T. L. Madden, A. A. Schäffer, J. Zhang, Z. Zhang, W. Miller, and D. J. Lipman. 1997. Gapped BLAST and PSI-BLAST: A new generation of protein database search programs. Nucleic Acid Res. 25:3389-3402.

Aslam, M., R. Jimenez-Flores, H. Y. Kim, and W. L. Hurley. 1994. Two-dimensional electrophoretic analysis of proteins of bovine mammary gland secretions collected during the dry period. J. Dairy Sci. 77:1529-1536.

Bairoch, A., and R. Apweiler. 2000. The SWISS-PROT protein sequence database and its supplement TREMBL in 2000. Nucleic Acid Res. 28:45-48.

Belloque, J., and G. M. Smith. 1998. Thermal denaturation of $\beta$ lactoglobulin. A 1H NMR study. J. Agric. Food Chem. 46:18051813.

Brownlow, S., J. H. M. Cabral, R. Cooper, D. R. Flower, S. J. Yewdall, I. Polikarpov, A. C. T. North, and L. Sawyer. 1997. Bovine $\beta$ lactoglobulin at 1.8 angstrom resolution-still an enigmatic lipocalin. Structure 5:481-495.

Busti, P., C. A. Gatti, and N. J. Delorenzi. 1998. Some aspects of $\beta$ lactoglobulin structural properties in solution studied by fluorescence quenching. Int. J. Biol. Macromol. 23:143-148.

Burova, T. V., Y. Choiset, V. Tran, and T. Haertlé. 1998. Role of free Cys121 in stabilization of bovine beta-lactoglobulin. B. Prot. Eng. 11:1065-1073.

CCP4. 1994. Collaborative Computational Project No. 4. Acta Cryst. D 50:760-763. 
Flower, D. R., A. C. T. North, and C. E. Sansom. 2000. The lipocalin protein family-structural and sequence overview. Biochim. Biophys. Acta 1482:9-24.

Fogolari, F., L. Ragona, L. Zetta, S. Romagnoli, C. G. de Kruif, and H. Molinari. 1998. Monomeric bovine $\beta$-lactoglobulin adopts a $\beta$ barrel fold at pH 2. FEBS Lett. 436:149-154.

Halttunen, M., M. Kamarainen, and H. Koistinen. 2000. Glycodelin: A reproduction-related lipocalin. Biochim. Biophys. Acta 1482:149-156.

Hambling, S. G., A. S. McAlpine, and L. Sawyer. 1992. $\beta$-Lactoglobulin. Pages 140-191 in Advanced Dairy Chemistry-I: Proteins. P. F. Fox, ed. Elsevier, London, UK.

Harris, B. L. 1997. Selection to increase $\beta$-lactoglobulin B variant in New Zealand dairy cattle. Pages 467-473 in Milk Protein Polymorphism. J. P. Hill and M. Boland, eds. International Dairy Federation, Brussels, Belgium.

Havea, P., H. Singh, and L. K. Creamer. 2001. Characterization of heat-induced aggregates of $\beta$-lactoglobulin, $\alpha$-lactalbumin, and bovine serum albumin in a whey protein concentrate environment. J. Dairy Res. 68:483-497.

Hill, J. P., M. Boland, and A. F. Smith. 1997. The effect of $\beta$-lactoglobulin variants on milk powder manufacture and properties. Pages 372-394 in Milk Protein Polymorphism. J. P. Hill and M. Boland, ed. International Dairy Federation, Brussels, Belgium.

Jameson, G. B., J. J. Adams, and L. K. Creamer. 2002. Flexibility, functionality and hydrophobicity of bovine $\beta$-lactoglobulins. Int. Dairy J. 12:319-329.

Kinsella, J. E., and D. M.Whitehead. 1989. Proteins in whey: Chemical, physical and functional properties. Adv. Food Nutr. Res. 33:343-438.

Kobayashi T, M. Ikeguchi, and S. Sugai. 2000. Molten globule structure of equine $\beta$-lactoglobulin probed by hydrogen exchange. J. Mol. Biol. 299:757-770.

Koistinen, H., R. Koistinen, M. Seppälä, T. V. Burova, Y. Choiset, and T. Haertlé. 1999. Glycodelin and $\beta$-lactoglobulin, lipocalins with a high structural similarity, differ in ligand binding properties. FEBS Lett. 450:158-162.

Kontopidis, G., C. Holt, and L. Sawyer. 2002. The ligand binding site of bovine $\beta$-lactoglobulin-Evidence for a function? J. Mol. Biol. 318:1043-1055.

Kraulis, P. J. 1991. MOLSCRIPT-A program to produce both detailed and schematic plots of protein structures. J. Appl. Cryst. 24:946-950.

Kuwata, K., M. Hoshino, S. Era, C. A. Batt, and Y. Goto. 1998. The $\alpha-\beta$ transition of $\beta$-lactoglobulin as evidenced by heteronuclear NMR. J. Mol. Biol. 283:731-739.

Lange, D. C., R. Kothari, R. C.Patel, and S. C. Patel. 1998. Retinol and retinoic acid bind to a surface cleft in bovine beta-lactoglobulin: A method of binding site determination using fluorescence resonance energy transfer. Biophys. Chem. 74:45-51.

Lovrien, R., and W. F. Anderson. 1969. Resolution of binding sites in $\beta$-lactoglobulin. Arch. Biochem. Biophys. 131:139-144.

Lyster, R. L. J. 1972. Reviews of the progress of dairy science. Section C. Chemistry of milk proteins. J. Dairy Res. 39:279-318.

MacKenzie, S. H., M. P. Roberts, K. H. Liu, J. J. E. Doré, and J. D. Godkin. 1997. Bovine endometrial retinol-binding protein secretion, mRNA expression and cellular localisation during the estrous cycle and early pregnancy. Biol. Reprod. 57:1445-1450.

Manderson, G. A., M. J. Hardman, and L. K. Creamer. 1999. Effect of heat treatment on bovine $\beta$-lactoglobulin $\mathrm{A}, \mathrm{B}$, and $\mathrm{C}$ explored using thiol availability and fluorescence. J. Agric. Food Chem. 47:3617-3627.

McKenzie, H. A., and W. H. Sawyer. 1967. Effect of $\mathrm{pH}$ on $\beta$-lactoglobulins. Nature 214:1101-1104.

McMeekin, T. L., B. D. Polis, E. S. Della-Monica, and J. H. Custer. 1949. A crystallization complex of $\beta$-lactoglobulin with dodecyl sulphate. J. Am. Chem. Soc. 71:3606-3609.

Mukhopadhyay, M., S. Sundereshan, C. Rao, and A. A. Karande. 2001. Placental protein 14 induces apoptosis in T cells but not monocytes. J. Biol. Chem. 276:28268-28273.

Muresan, S., A. van der Bent, and F. A. de Wolf. 2001. Interaction of $\beta$-lactoglobulin with small hydrophobic ligands as monitored by fluorometry and equilibrium dialysis: Nonlinear quenching effects related to protein-protein association. J. Agric. Food Chem. 49:2609-2618.

Narayan, M., and L. J. Berliner. 1997. Fatty acids and retinoids bind independently and simultaneously to $\beta$-lactoglobulin. Biochemistry 36:1906-1911.

Otwinowski, Z., and W. Minor. 1997. Processing of X-ray diffraction data collected in oscillation mode. Meth. Enzymol. 276:307-326.

Ouwehand, A. C., S. J. Salminen, M. Skurnik, and P. L. Conway. 1997. Inhibition of pathogen adhesion by beta-lactoglobulin. Int. Dairy J. 7:685-692.

Page, R. D. M. 1996. TreeView: An application to display phylogenetic trees on personal computers. Comp. Appl. Biosci. 12:357-358.

Papiz, M. Z., L. Sawyer, E. E. Eliopoulos, A. C. T. North, J. B. C. Findlay, R. Sivaprasadarao, T. A. Jones, M. E. Newcomer, and P. J. Kraulis. 1986. The structure of $\beta$-lactoglobulin and its similarity to plasma retinol-binding protein. Nature 324:383-385.

Passey, R. J., and A. G. Mackinlay. 1995. Characterization of a second, apparently inactive, copy of the bovine $\beta$-lactoglobulin gene. Eur. J. Biochem. 233:736-743.

Perez, M. D., C. Diaz de Villegas, L. Sanchez, P. Arando, J. M. Ena, and M. Calvo. 1989. Interaction of fatty acids with $\beta$-lactoglobulin and albumin from ruminant milk. J. Biochem. 106:1094-1097.

Perez, M. D., P. Puyol, J. M. Ena, and M. Calvo. 1993. Comparison of the ability to bind lipids of $\beta$-lactoglobulin and serum-albumin of milk from ruminant and non-ruminant species. J. Dairy Res. 60:55-63.

Qi, X. L., C. Holt, D. McNulty, D. T. Clarke, S. Brownlow, and G. R. Jones. 1997. Effect of temperature on the secondary structure of beta-lactoglobulin at ph 6.7, as determined by cd and ir spectroscopy: A test of the molten globule hypothesis. Biochem. J. 324:341-346.

Qin, B. Y., M. C. Bewley, L. K. Creamer, H. M. Baker, E. N. Baker, and G. B. Jameson. 1998a. Structural basis of the Tanford transition of bovine $\beta$-lactoglobulin. Biochemistry 37:14014-14023.

Qin, B. Y., L. K. Creamer, E. N. Baker, and G. B. Jameson. 1998b. 12 -Bromododecanoic acid binds inside the calyx of bovine $\beta$-lactoglobulin. FEBS Lett. 438:272-278.

QUANTA. 2000. Molecular Simulations Corporation (now Accelerys), San Diego, CA.

Ragona, L., F. Fogolari, L. Zetta, M. D. Perez, P. Puyol, C. G. de Kruif, F. Lohr, H. Ruterjans, and H. Molinari. 2000. Bovine $\beta$ lactoglobulin: Interaction studies with palmitic acid. Protein Sci. 9:1347-1356.

Sakai, K., K. Sakurai, M. Sakai, M. Hoshino, and Y. Goto. 2000. Conformation and stability of thiol-modified bovine beta-lactoglobulin. Protein Sci. 9:1719-1729.

Sakurai, K., and Y. Goto. 2002. Manipulating monomer-dimer equilibrium of bovine $\beta$-lactoglobulin by amino acid substitution. J. Biol. Chem. 277:25735-25740.

Sawyer, L. 2003. $\beta$-Lactoglobulin. Pages 319-386 in Advanced Dairy Chemistry I, 3rd ed. P. F. Fox and P. McSweeney, eds. Kluwer, Amsterdam, The Netherlands.

Sawyer, L., S. Brownlow, I. Polikarpov, and S. Y. Wu. 1998. $\beta$-Lactoglobulin: Structural studies, biological clues. Int. Dairy J. 8:65-72.

Sawyer, L., G. Kontopidis, and S. Y. Wu. 1999. $\beta$-Lactoglobulin: A three dimensional perspective. Int. J. Food Sci. Technol. 34:409-418.

Seppälä, M., R. N. Taylor, H. Koistinen, R. Koistinen, and E. Milgrom. 2002. Glycodelin: A major lipocalin protein of the reproductive axis with diverse actions in cell recognition and differentiation. Endocrine Rev. 23:401-430.

Sheldrick, G. M., and T. R. Schneider. 1997. SHELXL: High-resolution refinement. Meth. Enzymol. 277:319-343.

Skerra, A. 2000. Lipocalins as a scaffold. Biochim. Biophys. Acta 1482:337-350.

Tanaka, T., Y. Urade, H. Kimura, N. Eguchi, A. Nishikawa, and O. Hayaishi. 1997. Lipocalin-type prostaglandin D synthase (beta- 
trace) is a newly recognized type of retinoid transporter. J. Biol. Chem. 272:15789-15795.

Tanford, C., L. G. Bunville, and Y. Nozaki. 1959. The reversible transformation of $\beta$-lactoglobulin at $\mathrm{pH}$ 7.5. J. Am. Chem. Soc. 81:4032-4036.

Thomas, P. G. A., M. V. Leslie, and P. J. Hansen. 1992. Retinol binding protein is produced by the bovine endometrium and accumulates in uterine secretions in a progesterone-dependent manner. Anim. Reprod. Sci. 27:55-66.

Tilley, J. M. A. 1960. The chemical and physical properties of bovine $\beta$-lactoglobulin. Dairy Sci. Abstr. 22:111-125.

Uhrinova, S., M. H. Smith, G. B. Jameson, D. Uhrin, L. Sawyer, and P. N. Barlow. 2000. Structural changes accompanying pHinduced dissociation of the $\beta$-lactoglobulin dimmer. Biochemistry 39:3565-3574.
Wang, Q. W., J. C. Allen, and H. E. Swaisgood. 1997. Binding of retinoids to $\beta$-lactoglobulin isolated by bioselective adsorption. J. Dairy Sci. 80:1047-1053

Wang, Q. W., J. C. Allen, and H. E. Swaisgood. 1998. Protein concentration dependence of palmitate binding to $\beta$-lactoglobulin. J. Dairy Sci. 81:76-81.

Wang, Q. W., J. C. Allen, and H. E. Swaisgood. 1999. Binding of lipophilic nutrients to $\beta$-lactoglobulin prepared by bioselective adsorption. J. Dairy Sci. 82:257-264.

Widmer, A. 1997. WITNOTP: A computer program for molecular modelling. Sandoz AG, Basel, Switzerland.

Wishnia, A., and T. W. Pinder. 1966. Hydrophobic interactions in proteins. The alkane binding site of $\beta$-lactoglobulins A and B. Biochemistry 5:1534-1542.

Wu, S. Y., M. D. Pérez, P. Puyol, and L. Sawyer. 1999. $\beta$-Lactoglobulin binds palmitate within its central cavity. J. Biol. Chem. 274:170-174. 